\title{
Leakages and pressure relation: an experimental research
}

\author{
F. De Paola and M. Giugni \\ Department of Hydraulic, Geotechnical and Environmental Engineering, University of Naples "Federico II", \\ Italy \\ Correspondence to: F. De Paola (depaola@unina.it)
}

Received: 2 July 2012 - Published in Drink. Water Eng. Sci. Discuss.: 25 July 2012

Revised: 9 October 2012 - Accepted: 16 October 2012 - Published: 5 November 2012

\begin{abstract}
Leaks in water systems are presently a frequent and increasing event that involves cost increase and poor service, not compliant to quality standards and modern management criteria. The most recent data available in Italy, resumed into the report issued by Control Committee for Water Resources Use (CONVIRI), shows leakages with an average value of $37 \%$. It is therefore important, for maintenance perspective, to investigate occurrence and evolution of water leaks and the analytical link between leaks $Q_{p}$ and network pressure $P$, for a reliable calibration of water networks quali-quantitative simulation models. The present work reports the first results of an experimental campaign started at Laboratory of Hydraulics of Department of Hydraulics, Geotechnical and Environmental Engineering of University of Naples Federico II in order to analyze the features of $Q_{p}(P)$ relation, which are compared with other results issued in literature.
\end{abstract}

\section{Introduction}

Leaks in water systems are presently a frequent and increasing event causing cost increase and poor service levels not compliant to quality standards and modern management criteria. The most recent data available in Italy are resumed into the report issued by Control Committee for Water Resources Use (CONVIRI, 2010) which shows leakages between $21 \%$ and $61 \%$, with an average value around $37 \%$. The recovery of part of these lost water volumes would allow to acquire "new" resources and also economical benefits due to adduction, treatment and distribution cost savings. Losses reduction could obviously be achieved by well planned maintenance campaigns, both ordinary and extraordinary: they are, however, expensive actions from a financial perspective and are often not rewarded by the economical value of the recovered resource.

A different approach is to control network operation pressure by installing PRVs (Pressure Reducing Valves) or realizing District Meter Areas (DMAs). For this purpose it is important to analyze the forming and evolution mechanisms of water leaks and the analytical link between the leaks $Q_{p}$ and the network pressure $P$. An experimental research on these topics has been started at the Hydraulics Laboratory of Department of Hydraulics, Geotechnical and Environmental Engineering of University of Naples Federico II (De Paola et al., 2010; De Paola and Giugni, 2010), in order to investigate the parameters affecting the leakage/pressure relationship for different pipe materials. The present work gives a global summary of all the experimental tests conducted so far. In particular, results of the dynamic tests performed on steel and ductile iron pipes are presented, and compared to the other ones present in literature (Sendil and Al Dhowalia, 1992; Lambert, 2000; Thornton and Lambert, 2005; Greyvenstein and Van Zyl, 2006; Milano, 2006; Coetzer et al., 2006; Ferrante et al., 2010; Massari et al., 2012).

\section{Experimental set-up}

Experimental tests were carried out in the Hydraulics Laboratory high pressure circulation plant. The water discharge, detected by an electromagnetic flow meter, is led to a system of two parallel air vessels which allows to keep a constant pressure up to 10 bars, and from this to a cylindrical steel adductor $(800 \mathrm{~mm}$ diameter) connected to the test plumbing 

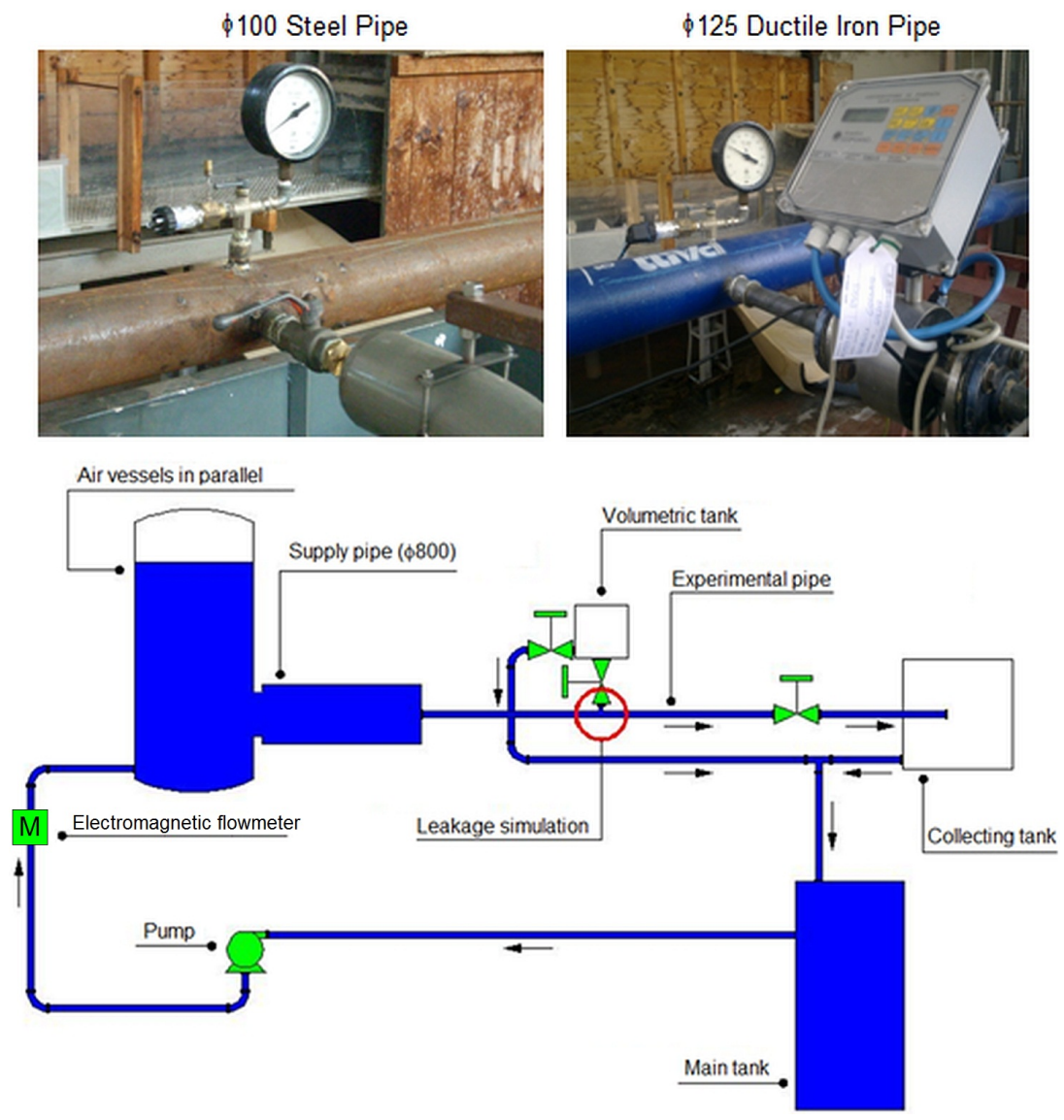

Figure 1. Experimental installation layout.

(Fig. 1). This latter in the first tests was a steel pipe $100 \mathrm{~mm}$ nominal diameter (DN 100) and thickness $s=4 \mathrm{~mm}, 6.70 \mathrm{~m}$ long and flat; in the second tests was a last generation ductile iron pipe (BLUTOP - PAM Saint Gobain) nominal diameter (DN 125) and thickness $s=3 \mathrm{~mm}$. The choice of the pipe materials at this early stage of the research is due to the the large use of steel and ductile iron pipes in Italian water distribution networks.

At the downstream end of the experimental duct was fitted a rubber wedge sluice valve (Fig. 1), connected to a PVC $\varnothing 110$ pipe which collects discharge to a recirculation tank. At $3.35 \mathrm{~m}$ downstream of the experimental pipe was installed a junction with an interception spherical valve at the end of which there is a nozzle used to simulate the occurrence of a leak (detail of Fig. 1).

This layout is assumed to reliably reproduce private connections in water distribution networks, where leakages due to metal pipe damages are more likely to occur. Furthermore the flow that is established in the pipe branch is surely a function of the geometry and the roughness of the main pipe. The boundary conditions must be taken into account and they are established only by the pressurized pipeline.
During the tests the water discharge flowing out of the nozzle is collected into a tank suitably calibrated, measuring filling time or, as alternative (for the ductile iron pipe), is measured by a small size electromagnetic flow meter (DN 25) (Fig. 1). Pressure measure is run by a WIKA transducer with a $0-10$ bar range and sample frequency equals to $10 \mathrm{~Hz}$.

In the tests the following parameters were varied:

1. feeding pressure, between 2 and 7 bars;

2. water discharge between 3 and $451 \mathrm{~s}^{-1}$;

3. nozzle geometry: the presence of leaks with different shape and size was simulated by using suitable nozzles: round, rectangular, square, irregular (Fig. 2);

aiming to achieve, by tests analysis, the water discharge and feeding pressure relationship.

\section{Experimental results}

Experimental tests were run with both static and dynamic approach, in order to simulate various operating conditions of a water system. The static tests simulate the night operating conditions (suitable to verify more precisely leaks occurrence), while the dynamic tests simulate day running. 

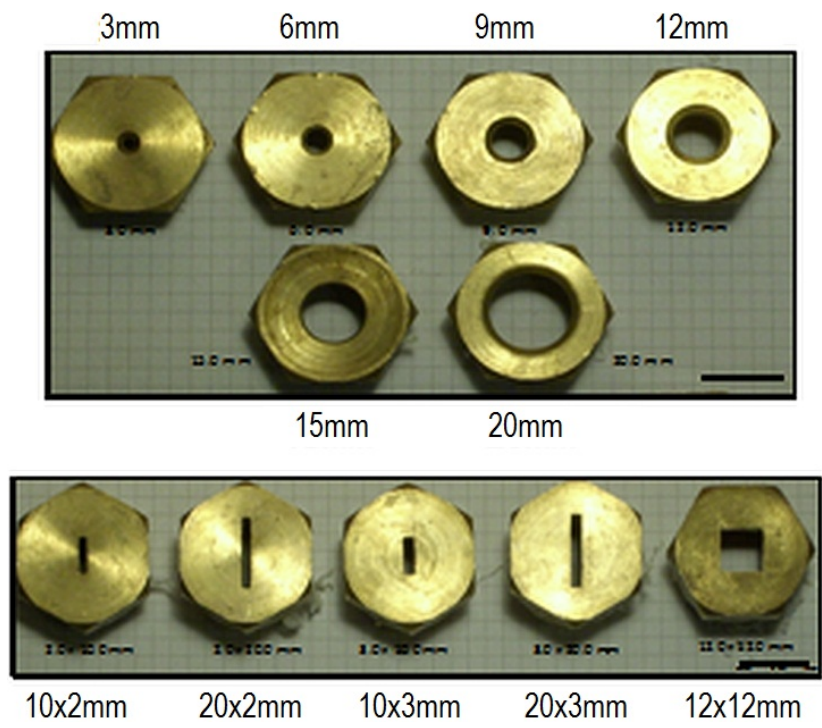

Figure 2. Test nozzles with different shape and size.

During each test, pressure was detected at least for $60 \mathrm{~s}$, in order to evaluate pressure variation features due to the leak.

\subsection{Steel pipe - static tests}

Generally a power law function is used to interpret the relation between water leaks $\left(Q_{P}\right)$ and pressure $(P)$ as follows:

$Q_{P}=a \cdot P^{b}$

In static tests conducted on steel pipe the driving pressure $P$ was varied in the range 2-7 bar, while the discharge $Q$ between 1 and 30 lps. The tests results allowed to calculate for the considered nozzle shapes, with a very high correlation rate $\left(R^{2}\right.$ always above 0.99), the values of coefficient $a$ and exponent $b$ in Eq. (1), as reported in Fig. 3. The coefficient $a$ in both cases increases, as obvious, according to nozzle size. The exponent $b$, instead, is always little far from the theoretical value 0.50 .

\subsubsection{Steel pipe - dynamic tests}

Dynamic tests allow to analyze, as already mentioned, the daily demand variation, by generating different discharge values (varying from about 3 to $45 \mathrm{lps}$ ) by the downstream valve. The tests duration was always about several minutes.

In these tests, leaks increase, as expected, as pressure and nozzle size increase. The exponent $b$ tends to a constant value, close but not equal to the theoretical value 0.50 , also for dynamic test conditions (Fig. 4).

It can be also highlighted that coefficient $a$ has an almost linear trend as surface ratio $A_{\mathrm{n}} / A_{\mathrm{p}}\left(A_{\mathrm{n}}=\right.$ nozzle area; $A_{\mathrm{p}}=$ pipe cross sectional area) varies for nozzles having either square or rectangular section, while for round section it shows a linear trend according to $d^{2} / D^{2}$ ratio and a parabolic trend according to $d / D$ ratio $(d=$ nozzle diameter; $D=$ pipe diameter) (Fig. 4) as also shown for the static tests.

\subsection{Ductile iron pipe}

In the first phase of experimental tests (steel pipe) the discharge was detected by a volumetric tank of small volume (see Fig. 1) and the duration of dynamic tests was therefore limited to few minutes. An evolution in the laboratory equipment was brought by introducing an electromagnetic flow meter on the pipe branch which allowed a continuous record of leakage discharge. The electromagnetic flowmeter, provided by Automation Progetti s.r.l., measures discharge in the range $0.047-5.55 \mathrm{lps}$ with a precision of $\pm 0.5 \%$ of the upper limit.

Experimental tests for ductile iron pipes were run in the already described way but with longer duration (almost $1 \mathrm{~h}$ ), in order to analyze leaks variations as discharge and pressure vary in the feeding pipe.

Figure 5 shows the close correlation between outflow discharge and pipe pressure for a rectangular $(10 \times 2 \mathrm{~mm})$ and a round $(6 \mathrm{~mm}$ diameter) nozzle. In Fig. 6 is also shown the time progress of flow experimental values compared to the points given by Eq. (1) after calibrating $a$ and $b$ coefficients using a Genetic Algorithm (GANetXL software, CWS, 2010). The GA was run varying at each iteration the $a$ and $b$ values in order to minimize the sum of the square differences between measured discharge at time $t$ and that obtained by Eq. (1) at the same time.

The model resulted very effective in the calculation of losses, and calibration leads to exponent $b$ values slightly lower than the theoretical value 0.50 .

The results of the dynamic tests performed on ductile iron pipe (Fig. 7) confirmed the findings of the tests carried out on steel pipe. For the $b$ exponent, tests indicate a substantial invariance, with values almost always slightly below 0.50 .

\section{Conclusive remarks}

Starting from the first experiments run in UK (Goodwin, 1980), the relation between water leaks and pressure ratio was analyzed through the monomial Eq. (1). Some research works afterwards developed in Saudi Arabia (Sendil and Al Dhowalia, 1992), UK (Burnell and Race, 2000) and Iran (Ardakanian and Ghazali, 2003) by the analysis of field data on different kind of pipes and different discharge range, confirmed such equation: available data are summarized in Table 1 , showing that exponent $b$ resulted systematically higher than 0.50 .

The experiments run so far in Naples for metal pipes, with pressure varying within a wide range not investigated in other experimental works, have shown as follows: 


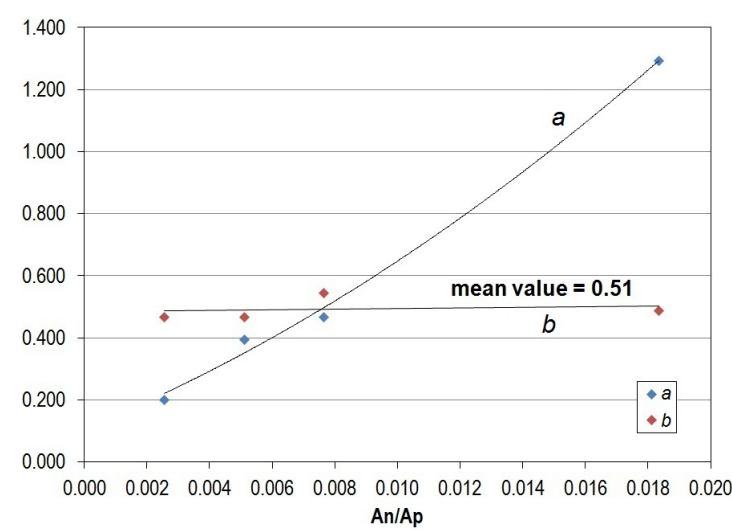

(3a)

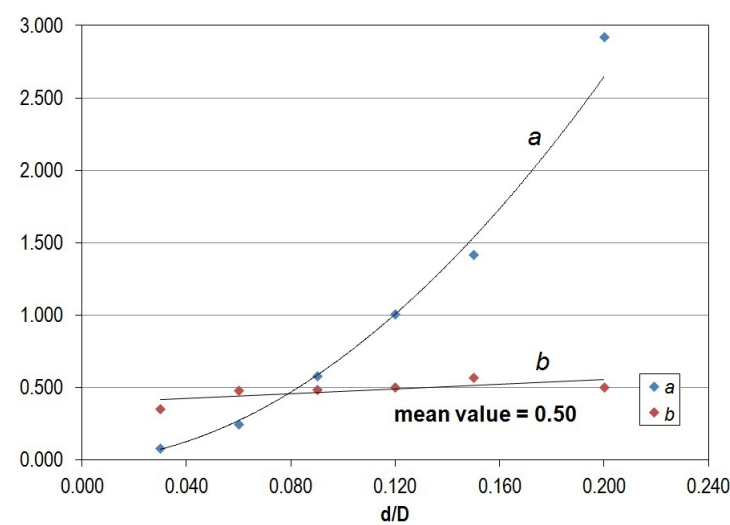

(3b)

Figure 3. Discharge coefficients according to: (a) surface ratio $A_{\mathrm{n}} / A_{\mathrm{p}}$ (rectangular nozzles); (b) diameter ratio $d / D$ (round nozzles). Static tests on steel pipe.

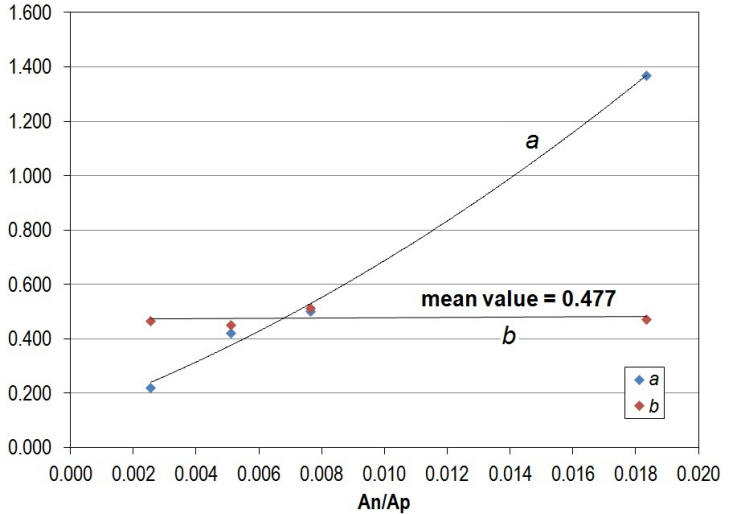

(4a)

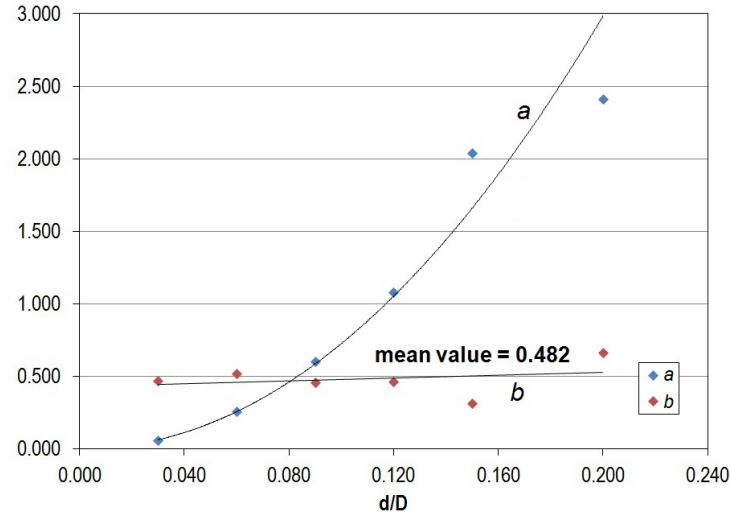

(4b)

Figure 4. Discharge coefficients according to: (a) $A_{\mathrm{n}} / A_{\mathrm{p}}$ ratio (rectangular nozzles); (b) $d / D$ ratio (round nozzles). Dynamic tests on steel pipe.

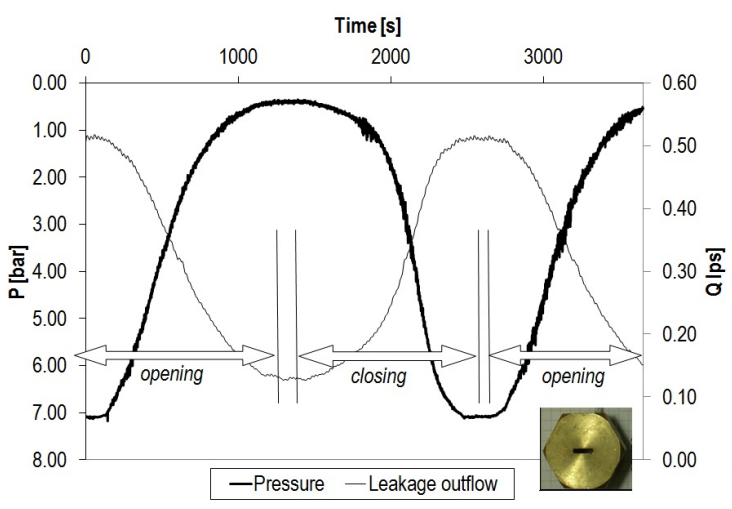

(5a)

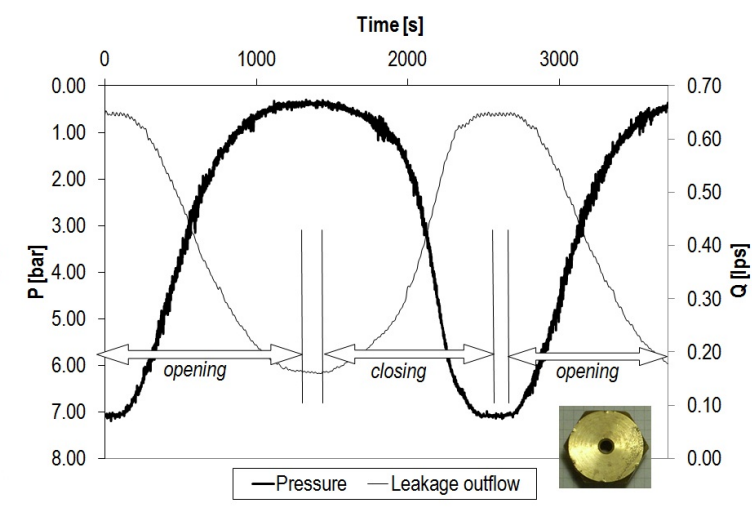

(5b)

Figure 5. Trend of detected pressures and outflow discharge for a rectangular (a) and a round (b) nozzle. 


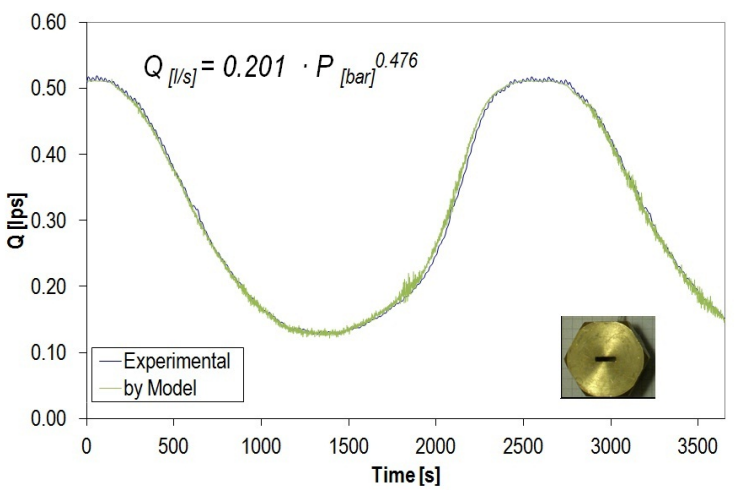

(6a)

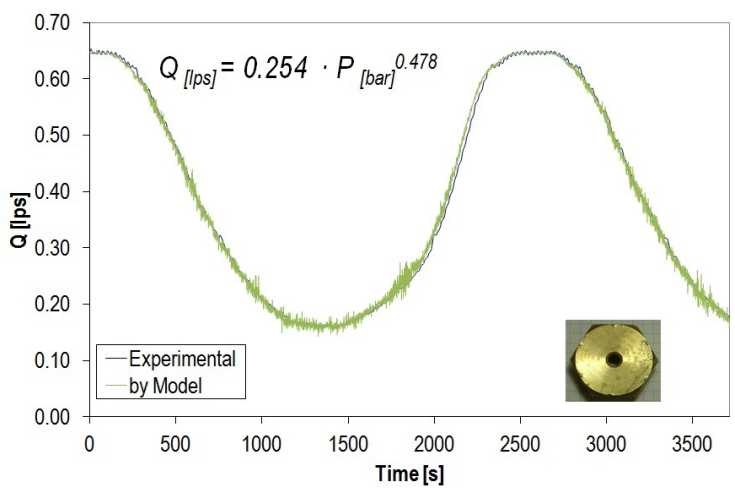

(6b)

Figure 6. Comparison between time series for measured outflows and model results after calibration (rectangular nozzles, $\mathbf{a}-$ round nozzle, b).

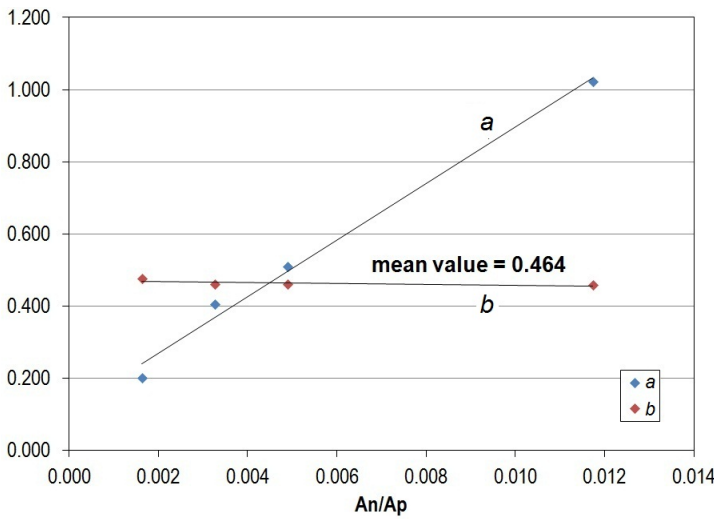

(7a)

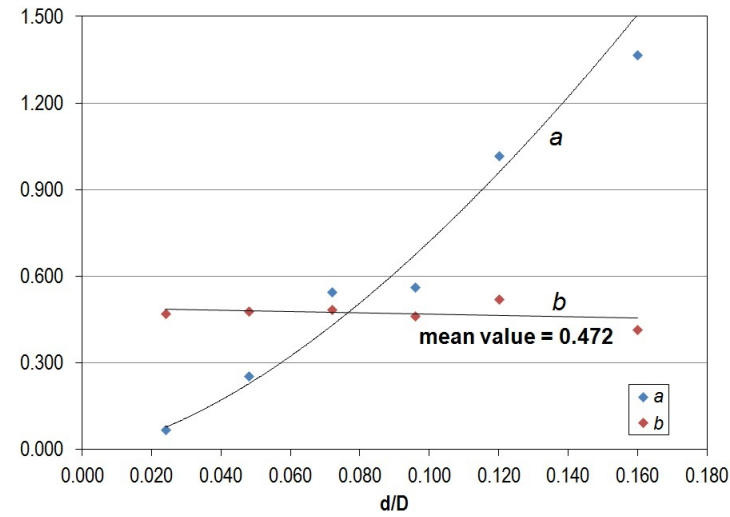

(7b)

Figure 7. Discharge coefficients according to: (a) $A_{\mathrm{n}} / A_{\mathrm{p}}$ ratio (rectangular nozzles); (b) $d / D$ ratio (round nozzles). Dynamic tests on ductile iron pipe.

- the relation (1) allows a reliable forecast of leaks depending on pressures, if $(a)$ and $(b)$ coefficients are suitably defined;

- $a$ values show an increasing trend with the size of the outflow orifice. Since the combination of the pressure and the pipe stiffness for metal pipes produces negligible strains around the hole there is a linear dependence from $A_{\mathrm{n}} / A_{\mathrm{p}}$ ratio, also for circular nozzles for which in Figs. 3, 4, 7 the influence of the only characteristic dimension (diameter $d$ ) was highlighted.

- $b$ exponent resulted little far from the theoretical value 0.50 for both round and rectangular nozzles;

- $b$ values resulted slightly dependent from test characteristics (static or long-term dynamic).

Experimental data collected in Naples so far, therefore, confirm the results achieved by other tests for steel pipes (Fig. 7) with round nozzles (Coetzer et al., 2006), with reference to a range of pressures slightly smaller.

The $b$ values significantly higher than 0.50 reported in literature are related instead to steel pipes affected by corrosion and asbestos cement or plastic pipes with longitudinal cracks. Probably they are due to a reduced consistence of material around the holes (due to corrosion) (Greyvenstein and Van Zyl, 2006) or to the remarkable flexibility of plastic pipes (Farley and Trow, 2003; Walski et al., 2006; Ferrante et al., 2010; Bovolin and Picciotti, 2008).

For pipes characterized by high elasticity, then it would be appropriate to refer to an equation that takes into account the pressure/area link of the hole (such as FAVAD equation, Cassa et al., 2010). The analysis is, however, further complicated by the viscoelastic characteristics of materials such as HDPE.

Nevertheless, in the authors opinion these topics require more investigations to discern if they depend on the physics of the problem or maybe there is a distortion induced by the 
Table 1. Exponent $b$ values as reported in literature.

\begin{tabular}{lll}
\hline Source & $b$ & Installation type \\
\hline UK (Goodwin, 1980) & 1.18 (average) & Operating districts with little night metered consumptions \\
\hline SaudiArabia (Sendil and Al Dhowalia, 1992) & $0.54-1.61$ & Ten operating districts in Riyadh \\
\hline ThamesWater (Burnell and Race, 2000) & 1.00 & Supply-pipe leakage patterns in over 2000 accurately-logged domestic sites \\
\hline Iran (Ardakanian and Ghazali, 2003) & $1.10-1.18$ & Old cast iron with high leakage in Sanadaj (Kurdistan) \\
\hline
\end{tabular}

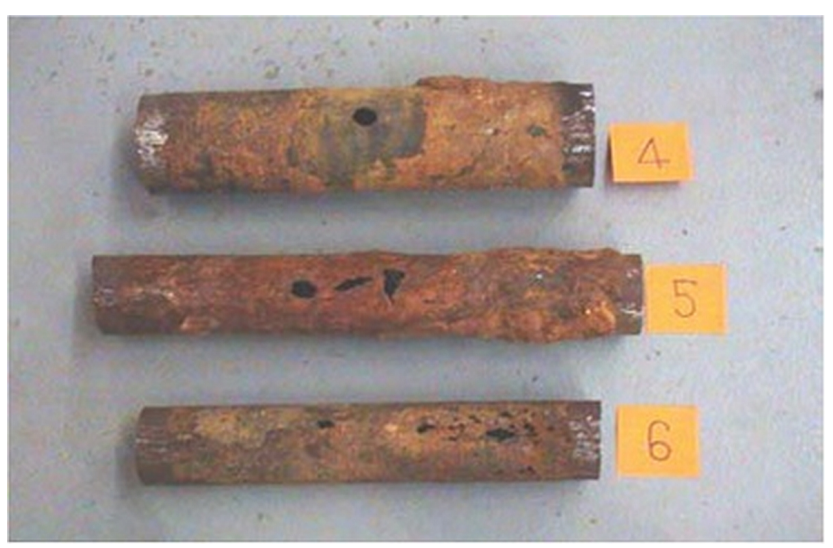

Figure 8. Corroded steel pipes (Greyvenstein and Van Zyl, 2006).

analysis of experimental data. For example, for steel pipes with holes caused by corrosion, the coefficients $b$ identified experimentally (Greyvenstein and van Zyl, 2006) for the pipes 4, 5 and 6 shown in Fig. 8 are, respectively, 0.67, 1.96 and 2.3 ; for an undamaged pipe, with the same mechanical properties, with an artificial hole diameter of $12 \mathrm{~mm}$, the identified coefficient is equal to 0.518 .

Further experiments are still in progress in the Hydraulics Laboratory of Naples on pipes of different materials (HDPE, GRP), in order to acquire new elements about the influence of the characteristics of the pipe and the features of the hole simulating the leak on the outflow mechanisms and, therefore, on the leakage law.

Acknowledgements. The Authors would like to thank the Editor Guangtao Fu, Kobus Van $\mathrm{Zyl}$ and the other anonymous reviewer for their suggestions, which improved the quality of this paper. They also thank Enzo Galdiero, Alfonso Stefanelli, Francesco Pace, Oriana Milito, Emanuele Mellucci for their contribution in performing the experimental tests.

Edited by: G. Fu

\section{References}

Ardakanian, R. and Ghazali, A. A.: Pressure-leakage relation in urban water distribution systems, Proceedings of the ASCE International Conference on Pipeline Engineering and Construction, Baltimore, 2003.

Bovolin, V. and Picciotti, M. V.: Analisi dei meccanismi relativi alle perdite idriche nelle reti in pressione, Proceedings of the 31 th Conference of Hydraulics and Hydraulic Engineering, Perugia, 1-10, 2008 (in Italian).

Burnell, D. and Race, J.: Water distribution systems analysis: patterns in supply-pipe leakage, Proceedings of the Joint Conference on Water Resources Engineering and Water Resources Planning \& Management, Minneapolis, 2000.

Cassa, A. M., Van Zyl, J. E., and Laubscher, R. F.: A numerical investigation into the effect of pressure on holes and cracks in water supply pipes, Urban Water J., 7, 109-120, 2010.

Centre for Water System (CWS): GANetXL User Manual, University of Exeter, 2010.

Coetzer, A. J., Van Zyl, J. E., and Clayton, C. R. I.: Experimental study of the hydraulics of small circular holes in water pipes, Proceedings of the 8th Annual Symposium on Water Distribution Systems Analysis Symposium, Cincinnati, Ohio, 27-30 August 2006.

Control Committee for Water Resources Use (CONVIRI): Rapporto sullo stato dei servizi idrici - Anno 2009, Rome, 2010 (in Italian).

De Paola, F. and Giugni, M.: Analisi sperimentale della relazione tra perdite e pressioni, Proceedings of the 32th Conference of Hydraulics and Hydraulic Engineering, 2010 (in Italian).

De Paola, F., Giugni, M., and Ranucci, A.: Analisi sperimentale della relazione tra perdite idriche e pressioni, Proceedings of the 4th Workshop "La ricerca delle perdite e la gestione delle reti di acquedotto", Aversa, 18-19 settembre 2009 (in Italian), 2010.

Farley, M. and Trow, S.: Losses in Water Distribution Networks, IWA Publishing, London, 2003.

Ferrante, M., Massari, C., Brunone, B., and Meniconi, S.: Analisi sperimentale della legge di perdita in condotte in acciaio e polietilene, Proceedings of the 32th Conference of Hydraulics and Hydraulic Engineering, 2010 (in Italian).

Goodwin, S. J.: The Results of the Experimental Programme on Leakage and Leakage Control, Technical Report TR 154, Water Research Centre, UK, 1980.

Greyvenstein, B. and Van Zyl, J. E.: An Experimental Investigation into the Pressure Leakage Relationship of some Failed Water Pipes, Water Institute of Southern Africa Biennial Conference, Durban, South Africa, 22-24 May 2006. 
Lambert, A.: What do we know about Pressure-Leakage Relationship in Distribution System?, Proceeding of the AWWA Conference on System Approach to Leakage Control and Water Distribution Systems Management, 2000.

Massari, C., Ferrante, M., Brunone, B., and Meniconi, S.: Is the head-discharge relationship in polyethylene pipes a bijective function?, J. Hydraul. Res., 50, 409-417, 2012.

Milano, V.: Dipendenza delle perdite di una tubazione dalla pressione di esercizio, L'Acqua, 4, 47-54, 2006 (in Italian).

Sendil, U. and Al Dhowalia, K. H.: Relationship between pressure and leakage in a water distribution network, Proceedings of the AWWA Conference, 1992.
Thornton, J. and Lambert, A.: Progress in practical prediction of pressure/leakage, pressure/burst frequency and pressure/consumption relationships, Proceedings of IWA Special Conference "Leakage 2005", Halifax, Canada, September, 2005. Walski, T., Betzts, W., Posluszny, E. T., Weir, M., and Whitmann, B. E.: Modeling leakage reduction through pressure control, J. AWWA, 98, 147-155, 2006. 